\title{
Peramalan Penjualan Rebung Bambu Betung (Dendrocalamus asper) Dengan Menggunakan Metode Triple Exponential Smoothing
}

\section{Sales Forecasting of Betung Bamboo Shoots (Dendrocalamus asper) by the use Triple Exponential Smoothing}

\author{
Ni Putu Murtini, I Gst Ngr Apriadi Aviantara*, Ida Bagus Putu Gunadnya \\ Program Studi Teknik Pertanian dan Biosistem, Fakultas Teknologi Pertanian Universitas Udayana, Badung, Bali, \\ Indonesia \\ *Email: apriadiaviantara@unud.ac.id
}

\begin{abstract}
Abstrak
Rebung bambu betung (Dendrocalamus asper) merupakan salah satu olahan produk segar yang dijual di Tiara Dewata Supermarket, dimana produk olahan tersebut terbagi menjadi tiga yaitu rebung mentah, rebung rajang, dan rebung biasa. Masa simpan rebung tergolong sangat singkat, hanya $1-3$ hari. Lebih lanjut, penjualan yang terjadi setiap bulan untuk ketiga produk segar ini berfluktuasi dan sulit diduga kecenderungannya. Oleh karena itu, diperlukan metode peramalan agar dapat memperkecil kerugian yang akan terjadi. Tujuan penelitian ini adalah menemukan nilai alfa terbaik yang dapat digunakan untuk memperoleh data runtun waktu peramalan yang terbaik untuk periode satu tahun mendatang terhadap ketiga jenis olahan rebung bambu betung dengan metode Triple Exponential Smoothing. Data yang digunakan pada penelitian ini yaitu data aktual penjualan ketiga olahan rebung bambu betung dari bulan Maret 2019 - Mei 2020. Nilai alfa terbaik yang dapat digunakan untuk melakukan peramalan yaitu perhitungan data runtun waktu dengan nilai alfa $0,1-0,9$ yang memiliki nilai kesalahan (error) terkecil, dimana alfa 0,4 pada rebung mentah dengan nilai kesalahan MSE 10,308, RSME 3,287, MAPE $19 \%$, alfa 0,4 pada rebung rajang dengan nilai kesalahan MSE 113,809, RMSE 10,688, MAPE 5\%, dan alfa 0,4 pada rebung biasa dengan nilai kesalahan MSE 511,902, RMSE 22,625, MAPE 4\%. Dari perhitungan menggunakan nilai alfa tersebut dapat disimpulkan bahwa metode triple exponential smoothing dengan alfa 0,4 digunakan untuk meramalkan data runtun waktu penjualan ketiga olahan rebung bambu betung dari periode Juni 2020 - Mei 2021.
\end{abstract}

Kata kunci: rebung bambu betung, berfluktuasi, peramalan, triple exponential smoothing, nilai alfa.

\begin{abstract}
Betung bamboo shoots (Dendrocalamus asper) is one of the processed fresh products sold at Tiara Dewata Supermarket, where the processed products are divided into three, namely raw bamboo shoots, chopped bamboo shoots, and ordinary bamboo shoots. The shelf life of bamboo shoots is very short, only 1-3 days. Furthermore, the monthly sales for these three fresh products fluctuate and it is difficult to predict the trend. Therefore, a forecasting method is needed in order to minimize the losses that will occur. The purpose of this study was to find the best alpha value that can be used to obtain the best time series forecasting data for the next one year for the three types of Betung bamboo shoots using the Triple Exponential Smoothing method. The data used in this study is the actual sales data of the three processed bamboo bamboo shoots from March 2019 - May 2020. The best alpha value that can be used for forecasting is the calculation of time series data with an alpha value of $0.1-0.9$ which has a value the smallest error, where alpha 0.4 in raw shoots with an error value of MSE 10.308, RSME 3.287, MAPE $19 \%$, alpha 0.4 in chopped bamboo shoots with an error value of MSE 113.809, RMSE 10.688, MAPE $5 \%$, and alpha 0,4 on ordinary shoots with an error value of MSE 511,902, RMSE 22,625, MAPE 4\%. From the calculation using the alpha value, it can be concluded that the triple exponential smoothing method with alpha 0.4 is used to predict the sales time series data of the three processed Betung bamboo shoots from the period June 2020 - May 2021.
\end{abstract}

Keyword: betung bamboo shoots, fluctuate, forecasting, triple exponential smoothing, alpha value. 


\section{PENDAHULUAN}

Bambu adalah jenis tanaman yang termasuk ke dalam rerumputan dan merupakan bagian dari komoditas hasil hutan bukan kayu karena memiliki beberapa keunggulan yaitu dapat dilengkungkan atau memiliki elastisitas dan dapat digunakan sebagai bahan dekorasi yang memiliki nilai jual yang tinggi (Arsad, 2015). Sekiranya terdapat $600-700$ jenis bambu di dunia, sekitar 125 jenis bambu terdapat di Indonesia dan sekitar 50 jenis bambu tersebut memiliki potensi yang sangat besar untuk dijadikan sebagai bahan kerajinan dan industri, karena bambu adalah tanaman yang multi fungsi dan cepat panen (Arsad, 2015).

Bambu Betung (Dendrocalamus asper) merupakan salah satu tanaman yang banyak tumbuh liar di hutan Indonesia diantaranya Pulau Jawa, Sumatera, Kalimantan, Sulawesi, dan Bali (Hingmadi, 2012). Bambu Betung (Dendrocalamus asper) ditanam dan tersebar di daerah dataran rendah sampai pegunungan, terutama di lembah atau jurang. Bambu betung menghasilkan rebung yang dimanfaatkan sebagai bahan makanan yang termasuk ke dalam golongan sayur - sayuran. Rebung yang dihasilkan berbeda dengan jenis rebung bambu lainnya karena memiliki rasa yang enak, tidak pahit, rebung yang besar dan tidak keras sehingga banyak diminati oleh masyarakat (Jong et al., 2018).

Rebung merupakan bagian dari tanaman bambu yang berupa tunas muda, dimana rebung muncul di bagian akar bambu. Rebung bambu memiliki fisik yang berbentuk kerucut dan biasanya dipenuhi dengan rambut halus yang gatal. Menurut Antara dan Gunam (2014) rebung memiliki kandungan air yang cukup besar yaitu 90,6\% serta memiliki kandungan serat yang tinggi. Jenis rebung yang biasa dikonsumsi di Indonesia yaitu jenis rebung bambu betung (Dendrocalamus asper), rebung bambu legi (Gigantochloa atter) dan rebung bambu tabah (Giganthochloa nigrociliata) (Kencana et al., 2012). Dengan kandungan air yang sangat tinggi tersebut menjadikan rebung mudah mengalami kerusakan setelah dipanen, untuk itu perlu diberikan penanganan lebih lanjut dalam mengatasi kerusakan tersebut yaitu dengan cara direbus, dijadikan asinan, dan divakum (Lestari, 2008).

Salah satu Supermarket besar yang ada di Bali yaitu Tiara Dewata Supermarket menjual Rebung Bambu Betung (Dendrocalamus asper) yang sebelumnya telah diolah dengan cara direbus dan dirajang mentah, dimana tiga jenis olahan rebung bambu betung tersebut yaitu rebung mentah, rebung rajang, dan rebung biasa. Rebung mentah yaitu rebung bambu betung yang sudah dibersihkan terlebih dahulu kemudian diiris tipis dan langsung dikemas mentah, rebung rajang yaitu rebung bambu betung yang sebelumnya dirajang membentuk persegi panjang dan direbus terlebih dahulu sebelum dikemas, dan rebung biasa yaitu rebung bambu betung yang direbus dan dipotong menjadi beberapa bagian degan ukuran yang cukup besar. Hasil penjualan rebung bambu betung di supermarket tersebut setiap bulannya berfluktuasi (naik - turun), sehingga diperlukan peramalan untuk memprediksi berapa stok rebung yang harus disiapkan dan agar dapat memperkecil jumlah kerugian yang akan terjadi jika terdapat banyak stok olahan rebung yang terbuang karena masa simpan yang dimiliki hanya dapat bertahan 1-3 hari.

Menurut Heizer dan Render dalam Indah dan Rahmadani, (2018) peramalan merupakan salah satu seni atau ilmu pengetahuan untuk memprediksi peristiwa pada masa mendatang. Peramalan Exponential Smoothing adalah salah satu metode yang melakukan perbaikan peramalan dengan mengambil nilai rata - rata penghalusan (smoothing) masa lalu dari suatu data runtut waktu dengan cara menurun. Metode Exponential Smoothing terbagi menjadi 3 yaitu Single, Double, dan Triple. Single Exponential Smoothing cocok digunakan untuk peramalan jangka pendek, Double Exponential Smoothing digunakan untuk meramalkan dua komponen yang harus diperbaiki yaitu trend dan level, dan Triple Exponential (peramalan kuadratis) digunakan untuk meramalkan data yang memiliki pola yang cenderung fluktuatif. Uji pola data dan kestasioneran diperlukan sebelumnya agar dapat menentukan pola data yang tepat pada data aktual penjualan rebung bambu betung sebelum menentukan metode peramalan yang akan digunakan.

Tujuan penelitian ini adalah menemukan nilai alfa terbaik yang dapat digunakan untuk memperoleh data runtun waktu peramalan terbaik yang dapat mendekati nilai aktual penjualan ketiga jenis olahan rebung bambu betung dan untuk membuat peramalan penjualan rebung bambu betung dengan metode Triple Exponential Smoothing untuk periode satu tahun mendatang.

\section{METODE}

\section{Tempat dan Waktu Penelitian}

Penelitian ini dilaksanakan di Tiara Dewata Supermarket, Jalan Mayjen Sutoyo No.55, Dauh Puri, Kecamatan Denpasar Barat, Kota Denpasar, Bali dan Laboratorium Sistem Manajemen Keteknikan Pertanian (SMKP), Prodi Teknik Pertanian dan Biosistem, Fakultas Teknologi Pertanian, Universitas 
Udayana. Penelitian ini dilakukan dengan mengambil data penjualan rebung bambu betung, dimana terdapat tiga jenis olahan rebung bambu betung yaitu rebung mentah, rebung rajang, rebung biasa. Penelitian ini dilaksanakan dari awal bulan Maret 2020 - akhir bulan Mei 2020.

\section{Alat dan Bahan}

Adapun alat dan bahan yang digunakan untuk memperlancar penelitian ini yaitu sebagai berikut:

Alat yang digunakan dalam penelitian ini untuk melakukan pengolahan data yaitu Laptop Asus Vivobook Max X441M dengan spesifikasi Intel Pentium Silver N5000, kecepatan prosesor $1.10 \mathrm{GHz}$ - $2.70 \mathrm{GHz}, 4 \mathrm{MB}$, standar memori 4GB DDR4, ukuran layar $14 \mathrm{inch}$, dan windows 10 . Alat lainnya yang digunakan untuk mengolah dan melakukan pengujian data yaitu Microsoft Excel 2016 dan Software Minitab.

Bahan yang digunakan dalam penelitian ini yaitu data aktual penjualan rebung bambu betung (Dendrocalamus asper) di Tiara Dewata Supermarket mulai dari bulan Maret 2019 - Mei 2020.

\section{Pembangunan Model}

Studi pendahuluan pada penelitian ini yaitu melakukan wawancara dengan pihak yang berwenang seperti kepala dan staf yang bertugas di bidang penjualan produk segar. Wawancara dilakukan untuk memperoleh informasi mengenai penjualan rebung bambu di Tiara Dewata Supermarket apakah sebelumnya sudah menerapkan metode peramalan untuk memprediksi penjualan di masa mendatang. Wawancara dilakukan dengan mengobrol langsung dengan pihak terkait dan menyampaikan beberapa pertanyaan.

Studi literatur pada penelitian ini diperoleh dari buku dan jurnal yang berisikan materi mengenai peramalan (forecasting), metode dan aplikasi peramalan, serta jurnal - jurnal yang berkaitan dengan bambu betung dan rebung bambu betung.

Materi yang diperoleh akan digunakan pada penelitian ini sebagai acuan dalam membuat pembahasan hasil peramalan yang akan dilakukan.

\section{Pengumpulan Data}

Dalam penelitian ini pengumpulan data dilakukan dengan pengamatan secara langsung di lapangan dengan memperoleh data primer yang berupa data kualitatif dan kuantitatif. Data kualitatif merupakan hasil wawancara dan informasi yang relevan mengenai segala jenis informasi yang berkaitan dengan rebung bambu yang dijual di supermarket tersebut seperti jenis rebung, supplier rebung bambu bambu betung, dan proses pengolahan rebung bambu yang dijual di supermarket tersebut. Data kuantitatif merupakan data deret waktu (time series) yang bersifat numerik, yaitu data aktual penjualan rebung bambu betung dari bulan Maret 2019 - Mei 2020 di Tiara Dewata Supermarket.

\section{Penggunaan Software Minitab}

Pada penelitian ini penggunaan software minitab bertujuan untuk mengetahui stasioner atau belum stasioner suatu data yang dimiliki dengan melakukan uji Autocorrelation Function (ACF) dan Partial Autocorrelation Function (PACF). Berdasarkan hasil pengujian tersebut akan dapat digunakan untuk menentukan pola data dan metode yang tepat digunakan untuk melakukan peramalan di periode mendatang.

\section{Analisis Data}

Perhitungan peramalan dengan menggunakan metode Triple Exponential Smoothing hal pertama yang dilakukan adalah menentukan nilai parameter alfa $(\alpha)$ yang akan digunakan yaitu $0<\alpha<1$. Indah dan Rahmadani, (2018) menyatakan bahwa semakin tinggi parameter alfa yang digunakan kepekaan ramalan akan semakin tinggi terhadap perubahan yang akan terjadi pada nilai yang sebenarnya (aktual) dan semakin kecil parameter alfa yang digunakan kepekaan ramalan terhadap perubahan pada nilai sebenarnya akan semakin rendah. Parameter alfa yang paling lazim digunakan adalah berkisar antara 0,1 - 0,5. Persamaan Triple Exponential Smoothing yang digunakan dalam melakukan peramalan yaitu sebagai berikut:

$$
\begin{aligned}
& \mathrm{S}_{\mathrm{t}}=\alpha \mathrm{X}_{\mathrm{t}}+(1-\alpha) \mathrm{S}_{\mathrm{t}-1}^{\prime} \\
& \mathrm{S}_{{ }_{\mathrm{t}}}=\alpha \mathrm{S}_{\mathrm{t}}+(1-\alpha) \mathrm{S}_{\mathrm{t}-1}+{ }_{\mathrm{t}}+1 \\
& \mathrm{~S}^{\prime}{ }_{\mathrm{t}}=\alpha \mathrm{S}^{\prime \prime}{ }_{\mathrm{t}}+(1-\alpha) \mathrm{S}^{\prime \prime \prime}{ }_{\mathrm{t}-1} \\
& \alpha_{\mathrm{t}}=3 \mathrm{~S}_{\mathrm{t}}^{\prime}-3 \mathrm{~S}^{\prime \prime}{ }_{\mathrm{t}}+\mathrm{S}^{\prime \prime \prime}{ }_{\mathrm{t}} \\
& \mathrm{b}_{\mathrm{t}}=\frac{\alpha}{2(1-\alpha)^{2}}\left[(6-5 \alpha) \mathrm{S}_{\mathrm{t}}-(10-8 \alpha) \mathrm{S}^{\prime \prime}{ }_{\mathrm{t}}\right. \\
& \left.\quad \quad+(4-3 \alpha) \mathrm{S}^{\prime \prime \prime}{ }_{\mathrm{t}}\right] \\
& \mathrm{c}_{\mathrm{t}}=\frac{\alpha^{2}}{(1-\alpha)^{2}}\left(\mathrm{~S}^{\prime}{ }_{\mathrm{t}}-\mathrm{S}^{\prime \prime}{ }_{\mathrm{t}}+\mathrm{S}^{\prime \prime \prime}{ }_{\mathrm{t}}\right) \\
& \mathrm{F}_{\mathrm{t}+\mathrm{m}}=\alpha_{\mathrm{t}}+\mathrm{b}_{\mathrm{t}} \mathrm{m}+\frac{1}{2} \mathrm{c}_{\mathrm{t}} \mathrm{m}
\end{aligned}
$$

\section{Dimana:}

S't : Nilai Pemulusan Pertama

S”t : Nilai Pemulusan Kedua

S"'t : Nilai Pemulusan Ketiga

$\mathrm{Xt} \quad$ : Nilai Aktual Penjualan

at,bt,ct : Konstanta Pemulusan

$\alpha \quad$ : Parameter Pemulusan Eksponensial $(0<\alpha<1)$

$\mathrm{m} \quad$ : Periode Masa Mendatang

$\mathrm{Ft}+\mathrm{m}$ : Hasil Peramalan Periode ke Depan 


\section{Kalibrasi dan Validasi}

Kalibrasi merupakan salah satu proses pengoptimalan atau secara sistematis menyesuaikan nilai parameter model untuk mendapatkan satu set parameter yang memberikan hasil terbaik dari proses peramalan yang dilakukan dengan metode Triple Exponential Smoothing (Mardhotillah et al., 2014). Data yang digunakan untuk pengujian kalibrasi merupakan data aktual penjualan rebung bambu betung dari bulan Maret 2019 - Desember 2019. Validasi diperlukan untuk memeriksa model yang telah disimulasikan sebelumnya (Rachmawati, 2016). Data yang digunakan untuk pengujian validasi yaitu data time series aktual penjualan rebung bambu betung dari bulan Januari 2020 - Mei 2020.

Menurut Hartini dalam Dharmesta dan Susanto, (2016) terdapat beberapa rumus yang dapat digunakan untuk menguji metode peramalan sehingga menghasilkan error ramalan yang relatif kecil yaitu diantaranya MSE, RMSE dan MAPE. Semakin kecil nilai kesalahan (error) yang dihasilkan, maka semakin tepat sebuah metode dalam memprediksi (Santoso, 2009 dalam Padma Yanti et al., 2016). Berikut merupakan metode perhitungan yang digunakan dalam pengujian kalibrasi dan validasi yaitu dengan MSE, RMSE dan MAPE.

$\mathrm{MSE}=\frac{\sum(A t-F t)^{2}}{n}$

$\mathrm{RSME}=\sqrt{\frac{\sum(A t-F t)^{2}}{n}}$

MAPE $=\frac{100}{n} \Sigma \frac{|A t-F t|}{A t}$

Dimana:
At : Nilai Aktual
Ft : Nilai Peramalan
n : Jumlah Periode Data

Berikut merupakan tabel mengenai kriteria dari perhitungan MAPE (Chang et al., 2007).

Tabel 1.Kriteria perhitungan Mean Absolute Percent Error (MAPE).

\begin{tabular}{cc}
\hline Nilai MAPE & Kriteria \\
\hline $10 \%-20 \%$ & Sangat Baik \\
$20 \%-50 \%$ & Baik \\
$>50 \%$ & Cukup \\
\hline
\end{tabular}

\section{HASIL DAN PEMBAHASAN}

\section{Data Aktual Penjualan Rebung Bambu Betung (Dendrocalamus asper) di Tiara Dewata Supermarket}

Data yang digunakan pada penelitian ini merupakan data penjualan Rebung Bambu Betung (Dendrocalamus asper) di Tiara Dewata Supermarket dari bulan Maret 2019 - Mei 2020 yang dapat dilihat pada Tabel 2. Terdapat tiga jenis olahan rebung bambu betung yang dipasarkan diantaranya rebung mentah, rebung rajang, dan rebung biasa.

Tabel 2.Data penjualan aktual ketiga jenis olahan rebung bambu betung (dendrocalamus asper) di Tiara Dewata Supermarket.

\begin{tabular}{lcccc} 
Bulan & Tahun & $\begin{array}{c}\text { Data } \\
\text { Rebung } \\
\text { Mentah } \\
\text { (Bks) }\end{array}$ & $\begin{array}{c}\text { Rebung } \\
\text { Rajang } \\
\text { (Bks) }\end{array}$ & $\begin{array}{c}\text { Rebung } \\
\text { Biasa } \\
\text { (Bks) }\end{array}$ \\
Mar & 2019 & & & \\
Apr & 2019 & 20 & 104 & 473 \\
Mei & 2019 & 32 & 154 & 511 \\
Jun & 2019 & 14 & 126 & 417 \\
Jul & 2019 & 17 & 175 & 361 \\
Agust & 2019 & 19 & 181 & 599 \\
Sep & 2019 & 12 & 84 & 485 \\
Okt & 2019 & 9 & 165 & 483 \\
Nov & 2019 & 11 & 124 & 430 \\
Des & 2019 & 21 & 164 & 404 \\
Jan & 2020 & 28 & 199 & 468 \\
Feb & 2020 & 39 & 168 & 485 \\
Mar & 2020 & 33 & 173 & 416 \\
Apr & 2020 & 23 & 147 & 349 \\
Mei & 2020 & 42 & 240 & 599 \\
\hline
\end{tabular}

Rebung mentah merupakan rebung bambu betung yang sudah dibersihkan terlebih dahulu kemudian diiris tipis dan langsung dikemas mentah. Rebung mentah memiliki warna putih bersih dan memiliki masa simpan yang hanya dapat bertahan selama 1 hari. Rebung rajang merupakan rebung bambu betung yang sebelumnya dirajang membentuk persegi panjang dan direbus terlebih dahulu sebelum dikemas. Rebung rajang memiliki warna yang agak kekuningan dan memiliki masa simpan yang sebentar yaitu selama 1 hari. Rebung biasa merupakan rebung bambu betung yang dipotong menjadi beberapa bagian dan direbus terlebih dahulu. Rebung mentah cara pengemasannya berbeda dengan kedua jenis olahan rebung sebelumnya karena saat dikemas air rebusan rebung biasa ikut dimasukkan ke dalam kemasan. Rebung biasa memiliki warna yang sedikit agak pucat dan memiliki masa simpan $2-3$ hari. 


\section{Identifikasi Pola Data}

Identifikasi pola data dapat dilakukan dengan pengamatan melalui penyajian grafik dari data aktual yaitu dengan data time series (Darmayanti, 2016). Terdapat empat jenis pola data yaitu Tren (Trend), Musiman (Seasonality), Acak (Random), dan Siklus (Cycles).

Pengujian pola data dengan mengamati penyajian secara grafik seperti yang dapat dilihat pada Gambar 1, Gambar 2, dan Gambar 3 menunjukkan bahwa data aktual penjualan rebung mentah, rajang dan biasa termasuk ke dalam pola data random (acak) karena dari data tersebut memiliki sifat yang berfluktuasi (naik turun) disekitar nilai rata - rata (mean) secara acak dari waktu ke waktu, dimana nilai mean yang dihasilkan yaitu pada rebung mentah 23,6 bungku, rebung rajang 154,5 bungkus, dan rebung biasa 461,3 bungkus. Pada data aktual penjualan tersebut juga tidak menunjukkan pola yang jelas seperti yang ditampilkan oleh pola data tren, musiman, dan siklus.

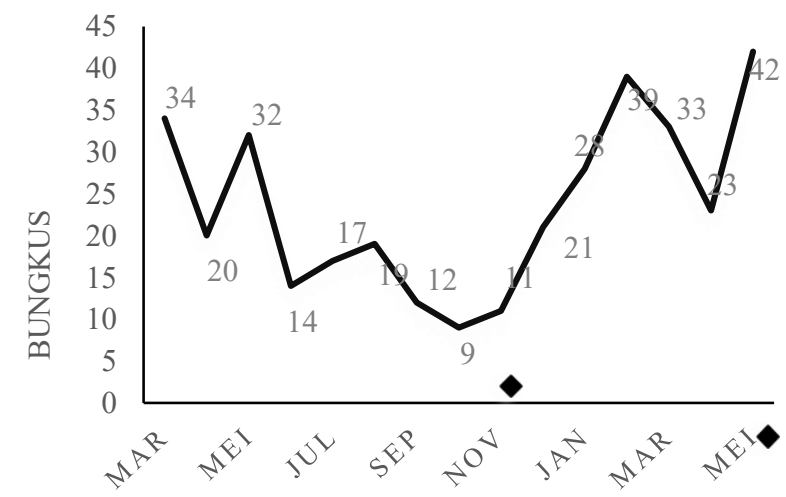

Gambar 1. Grafik data penjualan rebung mentah.

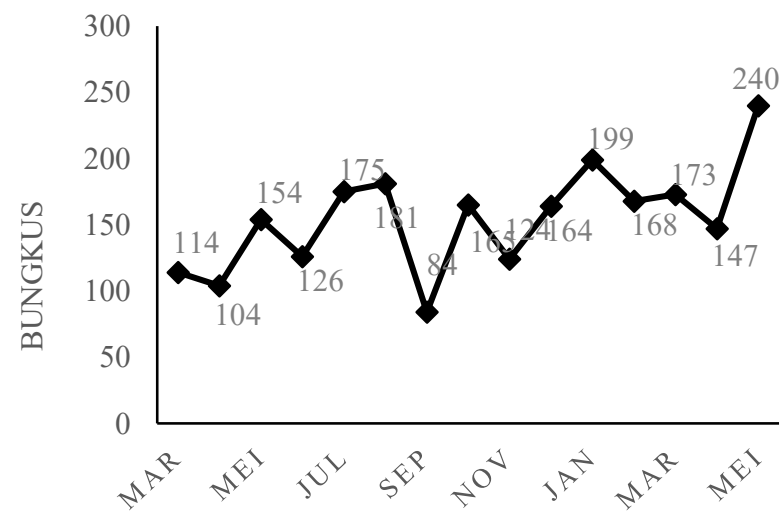

Gambar 2. Grafik data penjualan rebung rajang.

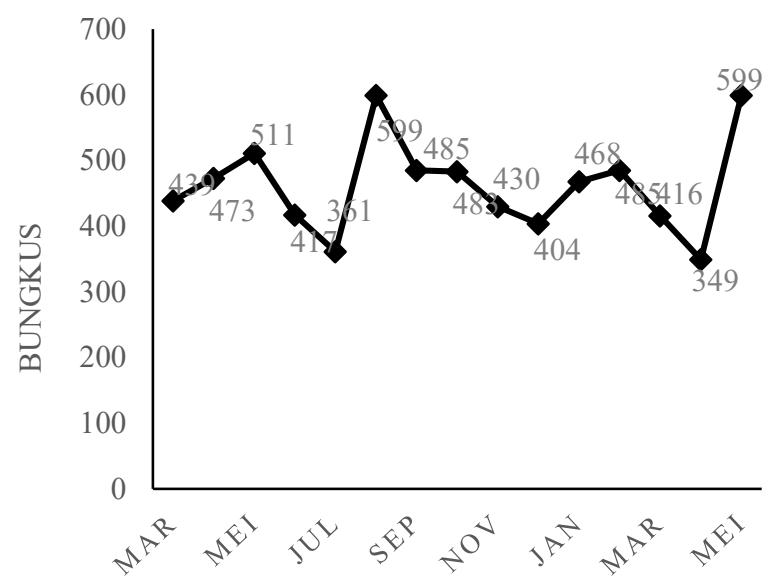

Gambar 3. Grafik data penjualan rebung biasa

Langkah lainnya yang dapat dilakukan untuk mengidentifikasi pola data yang tepat yaitu dengan menguji kestasioneran data. Menurut Rizal dan Akbar (2015) stasioner atau tidaknya suatu data dapat dilakukan dengan pengujian menggunakan metode Correlogram, dimana pada metode ini kriteria kestasioneran dapat dilihat pada plot Autocorrelation Funcion (ACF) dan Partial Autocorrelation Function (PACF). Elvierayani, (2017) menyatakan bahwa stasioneritas berarti bahwa tidak terdapat pertumbuhan atau penurunan pada data atau fluktuasi data berada disekitar nilai rata - rata yang konstan.

Pada hasil pengujian data dengan menggunakan Software Minitab untuk mengetahui hasil pengujian plot Autocorrelation Funcion (ACF), data dinyatakan stasioner jika memiliki nilai autokorelasi yang meluruh atau berkurang dengan cepat sampai mendekati angka nol mulai lag kedua atau ketiga, serta memiliki bentuk pola yang naik turun pada nilai autokorelasi yang bersifat positif dan negatif (Yulianti, 2012). Berdasarkan plot autokorelasi ACF yang dapat dilihat pada Gambar 4, Gambar 5, dan Gambar 6 menghasilkan data deret waktu penjualan ketiga jenis olahan rebung bambu betung yang sudah stasioner karena tepat setelah lag kedua atau ketiga nilai autokorelasi berkurang dengan cepat dan mendekati angka nol.

Menurut Faustina et al. (2017), pada plot Partial Autocorrelation Function (PACF) data yang keluar dari batas stasioner, menunjukkan bahwa data tidak atau belum stasioner. 
Berdasarkan plot autokerelasi PACF pada Gambar 4, Gambar 5, dan Gambar 6 menunjukkan bahwa tidak ada nilai autokorelasi yang melebihi garis stasioner (garis merah) yang berarti data penjualan olahan rebung mentah, rebung rajang, dan rebung biasa sudah stasioner.

Pada plot autokorelasi Autocorrelation Function (ACF) dan Partial Autocorrelation Function (PACF) sama - sama sudah stasioner dan tidak menunjukkan adanya unsur tren dan musiman melainkan menunjukkan residu yang bersifat acak (random). Menurut Firdaus dalam Tohir (2011), plot yang dihasilkan berpola trend ketika adanya beda kala pertama tinggi atau sangat menjauhi angka nol secara signifikan, sedangkan jika pola tersebut mengandung unsur musiman maka plot yang dihasilkan memiliki pola yang mendekati nol saat series meningkat serta memperlihatkan adanya pola gelombang secara bergantian antara positif dan negatif yang menunjukkan adanya unsur musiman.
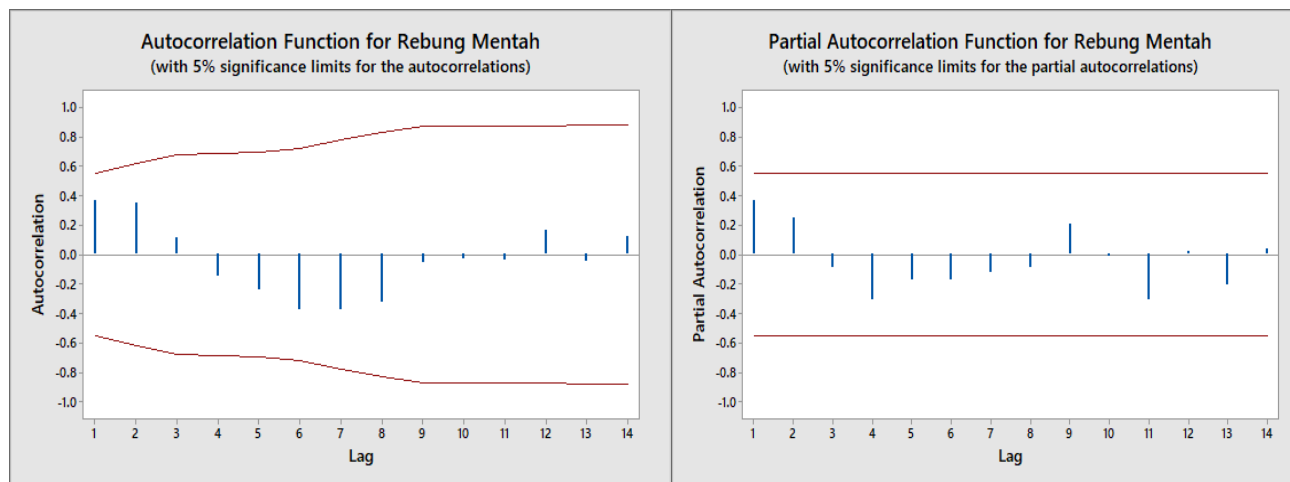

Gambar 4. Uji ACF dan PACF pada data aktual penjualan rebung mentah.
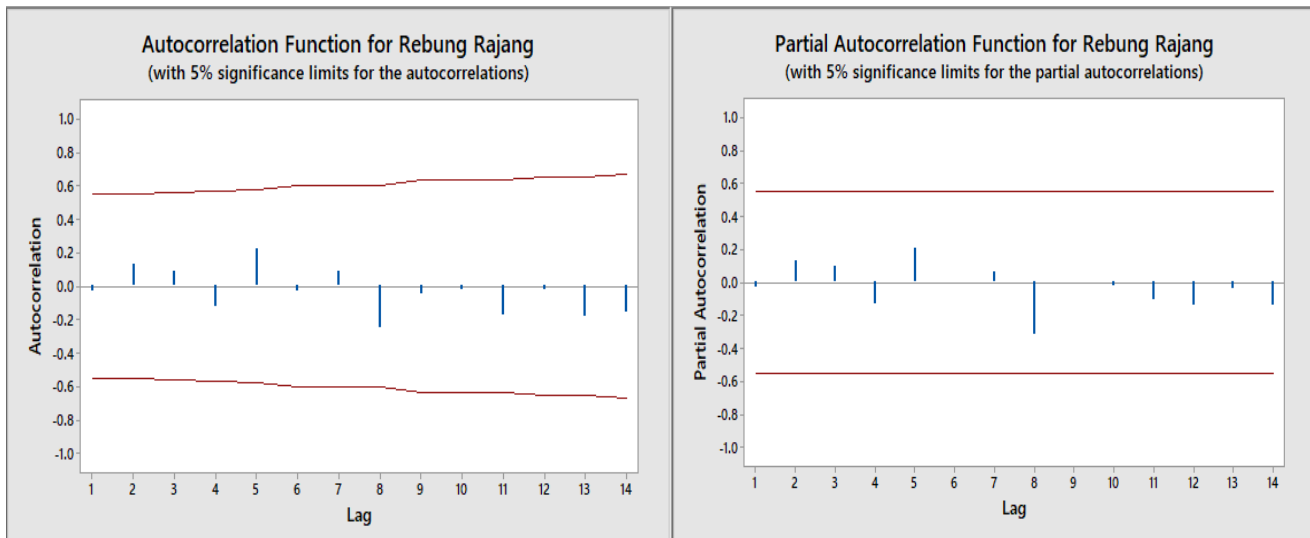

Gambar 5. Uji ACF dan PACF pada data aktualpenjualan rebung rajang.
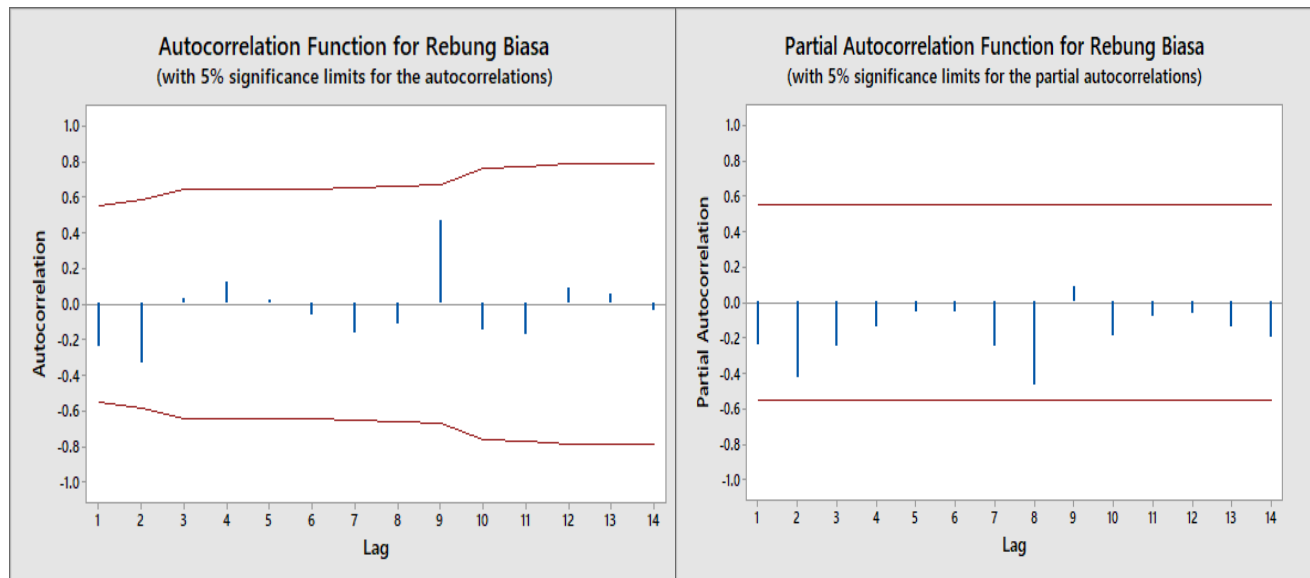

Gambar 6. Uji ACF dan PACF pada data aktual penjualan rebung biasa 


\section{Perhitungan Metode Triple Eksponential Smoothing}

Menurut Yulianti (2012) pola acak (random) merupakan pola yang pada saat data diobservasi berfluktuasi disekitar nilai rata - rata dan pola ini dapat juga disebut pola stasioner. Dengan demikian metode Triple Exponential Smooting cocok digunakan untuk membuat forecast dari suatu data yang berfluktuasi (naik-turun) (Makridakis et al., 1999).

Peramalan penjualan rebung bambu menggunakan metode Triple Exponential Smooting dilakukan dengan menggunakan Microsoft Excel 2016. Dalam melakukan perhitungan tersebut diperlukan parameter alfa $(\alpha)$ yang sesuai agar dapat memberikan hasil peramalan yang lebih mendekati nilai aktual.

Menurut Tistiawan dan Andini (2019) parameter pemulusan alfa tidak mendekati nol (0) akan berpengaruh pada hasil pemulusan eksponensial ketika digunakan untuk meramalkan siklus jangka panjang, Sedangkan jika alfa mendekati nol (0) akan dapat memainkan peranan yang nyata. Sehingga, nilai alfa yang digunakan yaitu $\alpha=0,1$ sampai $\alpha=0,9$, dimana nilai parameter alfa $(\alpha)$ besarnya antara $0<\alpha<1$. Nilai alfa yang biasanya paling lazim digunakan dalam perhitungan metode Triple Exponential Smoothing yaitu berkisar dari 0,1-0,5.

Menurut Ariyanto et al., (2017) dalam melakukan peramalan, parameter yang digunakan akan dapat berpengaruh terhadap nilai peramalan yang akan dihasilkan. Untuk mengetahui parameter alfa $(\alpha)$ yang terbaik digunakan, maka dapat dilakukan pengujian akurasi data terhadap hasil pengolahan data aktual penjualan ketiga jenis olahan rebung bambu betung dengan mencari nilai kesalahan (error) terkecil dari parameter alfa yang digunakan yaitu mulai dari $0,1-0,9$.

\section{Kalibrasi dan Validasi}

Dalam melakukan sebuah peramalan, hasil peramalan yang akan diperoleh tidak sepenuhnya akan menghasilkan data yang tepat. Untuk dapat mengetahui seberapa besar total keseluruhan nilai kesalahan (error), terlebih dahulu dilakukan perhitungan terhadap nilai kesalahan tiap bulannya dengan menggunakan persamaan berikut:

Error $=$ Data Aktual - Data Ramalan

Menurut Iqbal (2016), hasil selisih yang diperoleh dari perhitungan tersebut kemudian di Absolute-kan agar selisih nilai yang bernilai negatif dapat berubah menjadi nilai positif.

\section{Kalibrasi}

Menurut Rachmawati, (2016) kalibrasi diperlukan untuk memastikan korelasi antara data aktual dengan data peramalan untuk memperoleh analisi trend. Dalam kata lain kalibrasi merupakan proses penentuan parameter alfa yang paling sesuai, sehingga dapat menghasilkan perbandingan data aktual dengan data ramalan yang menunjukkan hasil paling baik (Marlina dan Juliani, 2015).

Pengujian kalibrasi menggunakan data aktual penjualan rebung bambu betung dari bulan Maret 2019 - Desember 2019. Pengujian kalibrasi menggunakan metode MSE (Mean Square Error), RMSE (Root Mean Square Error), dan MAPE (Mean Absolute Percent Error).

Tabel 3. Nilai kesalahan terkecil dan parameter alfa terbaik pada produk rebung mentah.

\begin{tabular}{c|c|cc}
$\begin{array}{c}\text { Parameter } \\
\text { Alfa }(\boldsymbol{\alpha})\end{array}$ & MSE & RMSE & MAPE \\
0,1 & 35,78619501 & 5,982156305 & 29 \\
0,2 & 22,22172471 & 4,713992439 & 25 \\
0,3 & 13,81083929 & 3,716293757 & 20 \\
0,4 & 10,80342535 & 3,286856455 & 19 \\
0,5 & 17,31990509 & 4,161719007 & 22 \\
0,6 & 37,655925337 & 6,136713564 & 29 \\
0,7 & 80,13404026 & 8,951761853 & 42 \\
0,8 & 159,965561 & 12,64774924 & 60 \\
0,9 & 305,7807669 & 17,4865882 & 80 \\
\hline
\end{tabular}

Pada Tabel 3. diperoleh hasil dari pengujian kalibrasi data peramalan terhadap olahan rebung mentah dengan menggunakan metode Triple Exponential Smoothing. Parameter alfa 0,4 merupakan yang terbaik digunakan untuk peramalan pada jenis produk olahan rebung mentah, karena pada saat dilakukan pengujian dengan menggunakan MSE (Mean Square Error) diperoleh nilai kesalahan (error) terkecil yaitu 10,80342535, dengan RMSE (Root Mean Square Error) sebesar 3,286856455, dan MAPE (Mean Absolute Percent Error) sebesar 19\%.

Tabel 4. Nilai kesalahan terkecil dan parameter alfa terbaik pada produk rebung rajang.

\begin{tabular}{cccc}
$\begin{array}{c}\text { Parameter } \\
\text { Alfa }(\boldsymbol{\alpha})\end{array}$ & MSE & RMSE & MAPE \\
\hline 0,1 & 650,03101 & 25,495706 & 16 \\
0,2 & 368,40127 & 19,193782 & 12 \\
0,3 & 170,43927 & 13,055239 & 8 \\
0,4 & 113,80897 & 10,668129 & 5 \\
0,5 & 302,54855 & 17,393923 & 11 \\
0,6 & 910,34736 & 30,171963 & 18 \\
0,7 & 2246,9062 & 47,401542 & 30 \\
0,8 & 4896,5005 & 69,974999 & 45 \\
0,9 & 9959,2705 & 99,796145 & 65 \\
\hline
\end{tabular}


Pada Tabel 4. terdapat hasil pengujian kalibrasi data peramalan dengan metode Triple Exponential Smoothing, dimana parameter alfa 0,4 merupakan yang terbaik digunakan untuk peramalan pada jenis produk rebung rajang karena pada saat dilakukan pengujian dengan menggunakan MSE (Mean Square Error) diperoleh nilai kesalahan (error) terkecil yaitu 113,80897, RMSE (Root Mean Square Error) sebesar 10,668129, dan MAPE (Mean Absolute Percent Error) sebesar 5\%.

Tabel 5. Nilai kesalahan terkecil dan parameter alfa terbaik pada produk rebung biasa.

\begin{tabular}{|cccc|}
$\begin{array}{c}\text { Parameter } \\
\text { Alfa }(\boldsymbol{\alpha})\end{array}$ & MSE & RMSE & MAPE \\
0,1 & 2769,758008 & 52,62849046 & 9 \\
0,2 & 1483,47294 & 38,51587906 & 7 \\
0,3 & 593,9779827 & 24,37166352 & 4 \\
0,4 & 511,9021771 & 22,62525529 & 4 \\
0,5 & 1599,029842 & 39,98787118 & 7 \\
0,6 & 4334,710692 & 65,83851982 & 11 \\
0,7 & 9493,41173 & 97,43414048 & 15 \\
0,8 & 18377,83143 & 135,5648606 & 20 \\
0,9 & 33221,70526 & 182,2682234 & 24 \\
\hline
\end{tabular}

Pada Tabel 5. diperoleh hasil pengujian kalibrasi data terhadap peramalan rebung biasa dengan menggunakan metode Triple Exponential Smoothing.
Parameter alfa 0,4 merupakan yang terbaik digunakan untuk peramalan pada jenis produk rebung biasa, karena pada saat dilakukan pengujian dengan menggunakan MSE (Mean Square Error) diperoleh nilai kesalahan (error) terkecil yaitu 511,9021771, RMSE (Root Mean Square Error) sebesar 22,62525529, dan MAPE (Mean Absolute Percent Error) sebesar 4\%.

\section{Validasi}

Menurut Indarto dalam Mardhotillah et al., (2014) validasi merupakan suatu proses evaluasi terhadap model untuk mendapatkan gambaran tentang tingkat ketidakpastian yang dimiliki oleh suatu model dalam memprediksi. Data yang digunakan adalah data time series aktual penjualan rebung bambu betung dari bulan Januari 2020 - Mei 2020.

Pengujian validasi menggunakan metode MSE (Mean Square Error), RMSE (Root Mean Square Error), dan MAPE (Mean Absolute Percent Error). Metode MAPE memiliki kriteria perhitungan yang selanjutnya dapat digunakan untuk mengetahui apakah pengolahan data dengan parameter alfa yang digunakan untuk melakukan peramalan terhadap olahan rebung mentah, rebung rajang, dan rebung biasa baik atau tidak digunakan. Kriteria MAPE dapat dilihat pada Tabel 1 .

Tabel 6. Validasi model peramalan penjualan terhadap rebung mentah

\begin{tabular}{lcccc|cc}
\multicolumn{1}{c}{ Bulan } & Tahun & Aktual & Ramalan & MSE & RMSE & $\begin{array}{c}\text { MAPE } \\
(\%)\end{array}$ \\
Januari & & & & & & 0,216 \\
Februari & & 28 & 34 & 36,457 & 6,0379931 & 0,247 \\
Maret & 39 & 49 & 92,548 & 9,6201851 & 0,279 \\
April & 2020 & 33 & 42 & 84,952 & 9,2169251 & 0,115 \\
Mei & 23 & 26 & 7,017 & 2,6488718 & 0,028 \\
\hline \multicolumn{7}{c}{} \\
& 42 & 43 & 1,411 & 1,1876502 & 0,885 \\
\hline \multicolumn{7}{c}{ Total } \\
\hline
\end{tabular}

Tabel 6. merupakan hasil validasi pengolahan data penjualan terhadap rebung mentah dengan metode Triple Exponential Smoothing alfa 0,4. Validasi yang dilakukan memperoleh hasil pengujian MSE sebesar 44,47681291, RMSE sebesar 5,7423250, dan MAPE sebesar $18 \%$.

Berdasarkan hasil pengujian MAPE yang dilakukan diperoleh hasil sebesar 18\% yang berarti peramalan dengan menggunakan metode Triple Exponential Smoothing dengan parameter alfa 0,4 termasuk ke dalam kriteria yang baik digunakan untuk melakukan peramalan terhadap penjualan olahan rebung mentah. Kriteria MAPE tersebut dapat dilihat pada tabel 1.

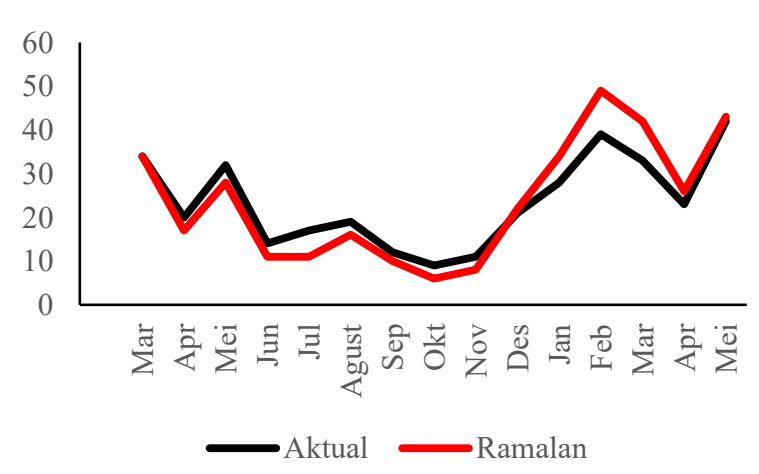

Gambar 7. Grafik perbandingan data aktual penjualan dengan data ramalan penjualan olahan rebung mentah dari bulan Maret 2019 - Mei 2020. 
Parameter alfa 0,4 yang digunakan dalam perhitungan terhadap data aktual penjualan rebung mentah memperlihatkan bahwa data peramalan yang dihasilkan dapat mengikuti fluktuasi dan mendekati data aktual penjualan seperti yang dapat dilihat pada gambar 7.

Tabel 7. Validasi model peramalan penjualan terhadap rebung rajang

\begin{tabular}{|c|c|c|c|c|c|c|}
\hline Bulan & Tahun & Aktual & Ramalan & MSE & RMSE & $\begin{array}{c}\text { MAPE } \\
(\%)\end{array}$ \\
\hline Januari & & 199 & 215 & 258,86440 & 16,08926 & 0,081 \\
\hline Februari & & 168 & 186 & 322,69137 & 17,96361 & 0,107 \\
\hline Maret & 2020 & 173 & 179 & 31,18574 & 5,584419 & 0,032 \\
\hline April & & 147 & 143 & 15,82023 & 3,977466 & 0,027 \\
\hline Mei & & 240 & 246 & 37,57113 & 6,129529 & 0,026 \\
\hline \multicolumn{4}{|c|}{ Total } & 666,133 & 49,74429 & 0,273 \\
\hline \multicolumn{4}{|c|}{ Hasil Akhir Pengujian } & 133,226575 & 9,948858053 & 5 \\
\hline
\end{tabular}

Tabel 7. merupakan hasil validasi pengolahan data penjualan terhadap rebung rajang dengan metode Triple Exponential Smoothing alfa 0,4. Validasi yang dilakukan memperoleh hasil pengujian MSE sebesar 133,226575 , RMSE sebesar 9,948858053, dan MAPE sebesar 5\%.

Berdasarkan hasil pengujian MAPE yang dilakukan diperoleh hasil sebesar 5\% yang berarti peramalan dengan menggunakan metode Triple Exponential Smoothing dengan nilai alfa 0,4 termasuk ke dalam kriteria yang sangat baik digunakan untuk melakukan peramalan terhadap penjualan olahan rebung rajang. Kriteria MAPE tersebut dapat dilihat pada tabel 1.

Parameter alfa 0,4 yang digunakan dalam perhitungan terhadap data aktual penjualan rebung rajang memperlihatkan bahwa data peramalan yang

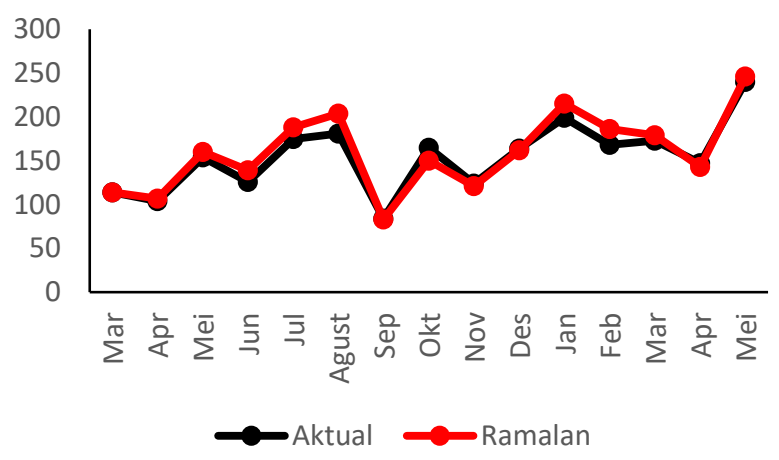

Gambar 8. Grafik perbandingan data aktual penjualan dengan data ramalan penjualan olahan rebung rajang dari bulan Maret 2019 - Mei 2020.

dihasilkan dapat mengikuti fluktuasi dan mendekati data aktual penjualan seperti yang dapat dilihat pada gambar 8 .

Tabel 8. Validasi model peramalan penjualan terhadap rebung biasa

\begin{tabular}{|c|c|c|c|c|c|c|}
\hline Bulan & Tahun & Aktual & Ramalan & MSE & RMSE & $\begin{array}{c}\text { MAPE } \\
(\%)\end{array}$ \\
\hline Januari & & 468 & 445 & 520,879848 & 16,08926 & 0,04877 \\
\hline Februari & & 485 & 491 & 40,764872 & 17,96361 & 0,01316 \\
\hline Maret & 2020 & 416 & 419 & 7,593303 & 5,584419 & 0,00662 \\
\hline April & & 349 & 320 & 867,724784 & 3,977466 & 0,08440 \\
\hline Mei & & 599 & 485 & 13043,306149 & 6,129529 & 0,19066 \\
\hline \multicolumn{4}{|c|}{ Total } & 14480,269 & 49,74429 & 0,344 \\
\hline \multicolumn{4}{|c|}{ Hasil Akhir Pengujian } & 2896,053791 & 35,125518 & 7 \\
\hline
\end{tabular}

Tabel 8. merupakan hasil validasi pengolahan data penjualan terhadap rebung biasa dengan metode Triple Exponential Smoothing alfa 0,4. Validasi yang dilakukan memperoleh hasil pengujian MSE sebesar 2896,053791, RMSE sebesar 35,125518, dan MAPE sebesar $7 \%$.
Berdasarkan hasil pengujian MAPE yang dilakukan diperoleh hasil sebesar 7\% yang berarti peramalan dengan menggunakan metode Triple Exponential Smoothing dengan nilai alfa 0,4 termasuk ke dalam kriteria yang sangat baik digunakan untuk melakukan peramalan terhadap penjualan olahan rebung biasa. Kriteria MAPE tersebut dapat dilihat pada tabel 1. 


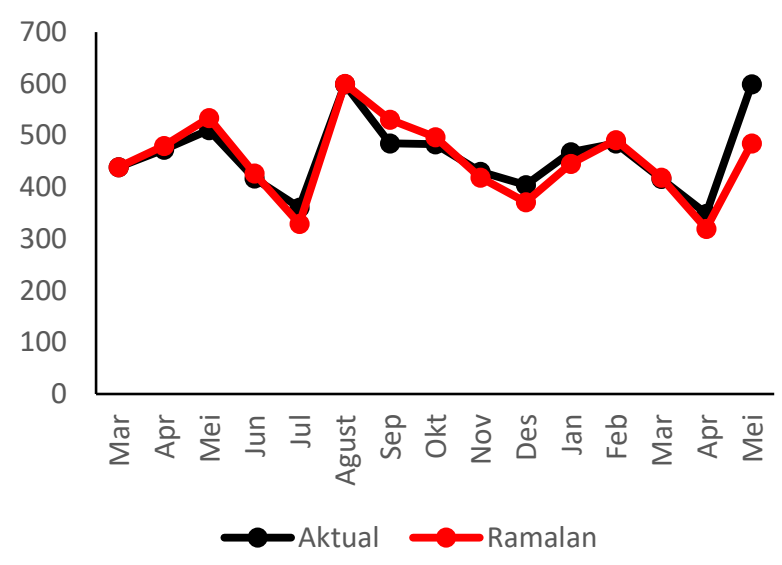

Gambar 9. Grafik perbandingan data aktual penjualan dengan data ramalan penjualan olahan rebung biasa dari bulan Maret 2019 - Mei 2020.

Parameter alfa 0,4 yang digunakan dalam perhitungan terhadap data aktual penjualan rebung biasa memperlihatkan bahwa data peramalan yang dihasilkan dapat mengikuti fluktuasi dan mendekati data aktual penjualan seperti yang dapat dilihat pada gambar 9 .

\section{Hasil Peramalan Pada Periode Satu Tahun Mendatang}

Peramalan dengan menggunakan metode Triple Exponential Smoothing untuk bulan atau tahun berikutnya dapat dilakukan jika parameter alfa terbaik yang memiliki nilai kesalahan terkecil sudah ditemukan. Menurut Tanuwijaya, (2010) keunggulan metode Exponential Smoothing dapat memberikan ketepatan dalam ramalan jangka pendek. Keunggulan dari metode Triple Exponential Smoothing merupakan metode forecast yang menggunakan persamaan kuadrat, sehingga dapat menghasilkan data peramalan yang semakin mendekati data aktual (Nangi et al., 2018).

Menurut Wardah dan Iskandar (2017) peramalan jangka pendek lebih akurat dari pada peramalan jangka panjang, karena peramalan jangka pendek, kondisi yang mempengaruhi permintaan cenderung tetap atau berubah lambat, sehingga peramalan jangka pendek lebih akurat.
Tabel 9. Hasil peramalan penjualan olahan rebung mentah, rebung rajang, dan rebung biasa mulai dari bulan Juni 2020 - Mei 2021

\begin{tabular}{lccc|c|}
\hline & \multicolumn{4}{c|}{ Hasil Peramalan } \\
Bulan & Tahun & $\begin{array}{c}\text { Rebung } \\
\text { Mentah } \\
\text { (Bks) }\end{array}$ & $\begin{array}{c}\text { Rebung } \\
\text { Rajang } \\
(\text { Bks) }\end{array}$ & $\begin{array}{c}\text { Rebung } \\
\text { Biasa } \\
(\text { Bks) }\end{array}$ \\
\hline Jun & 2020 & 48 & 277 & 681 \\
Jul & 2020 & 52 & 312 & 769 \\
Agust & 2020 & 57 & 350 & 868 \\
Sep & 2020 & 62 & 392 & 979 \\
Okt & 2020 & 67 & 438 & 1102 \\
Nov & 2020 & 73 & 487 & 1236 \\
Des & 2020 & 78 & 540 & 1381 \\
Jan & 2021 & 83 & 597 & 1538 \\
Feb & 2021 & 89 & 658 & 1706 \\
Mar & 2021 & 94 & 723 & 1886 \\
Apr & 2021 & 100 & 791 & 2077 \\
Mei & 2021 & 106 & 863 & 2280 \\
\hline
\end{tabular}

Berdasarkan hasil peramalan pada Tabel 9. dapat dilihat bahwa penjualan tidak berfluktuasi untuk satu tahun ke depan melainkan stabil dan mengalami peningkatan setiap bulannya. Peramalan dengan menggunakan metode triple exponential smoothing akan menghasilkan peramalan yang cukup stabil meskipun jumlah periode ramalan ditambah (Fitria dan Anwar, 2020). Total peramalan penjualan diperiode satu tahun mendatang pada olahan rebung mentah yaitu mencapai 910 bungkus, rebung rajang mencapai 6.428 bungkus, dan rebung biasa yang mencapai 16.503 bungkus.

\section{KESIMPULAN DAN SARAN}

\section{Kesimpulan}

Berdasarkan penelitian yang sudah dilakukan dapat disimpulkan bahwa parameter alfa terbaik terhadap peramalan rebung mentah, rebung rajang, dan rebung biasa diperoleh berdasarkan pengujian kalibrasi yang dilakukan, dimana parameter alfa tersebut adalah 0,4. Peramalan dengan menggunakan nilai alfa tersebut dapat menghasilkan data ramalan yang mendekati atau dapat mengikuti fluktuasi data aktual penjualan. Peramalan jangka pendek satu tahun mendatang yang dilakukan terhadap data aktual penjualan ketiga jenis olahan rebung bambu betung, menghasilkan data ramalan yang mengalami peningkatan setiap bulannya dengan stabil yang dimulai dari periode bulan Juni 2020 - Mei 2021. 


\section{Saran}

Diharapkan produsen dan ritailer dapat menggunakan metode peramalan Triple Exponential Smoothing sebagai acuan untuk merencanakan jumlah stok olahan rebung bambu betung yang harus disiapkan agar tidak terjadi kelebihan maupun kekurangan stok penjualan yang dapat menimbulkan kerugian mengingat olahan rebung bambu betung yang dijual memiliki masa simpan yang sebentar dan penjualan yang berfluktuasi secara tidak terduga.

\section{DAFTAR PUSTAKA}

Anggraini, Y. D. 2018. Analisis Data Runtun Waktu Untuk Peramalan Penjualan Sepeda Motor Di Indonesia Menggunakan Metode Fuzzy Time Series Dengan Logika Ruey Chyn Tsaur.

Antara, N. S., dan Gunam, I. B. W. 2014. Pengembangan Tepung Rebung Bambu tabah (Gigantochloa nigrociliata BUSE - KURZ) Sebagai Pangan Fungsional. Ketahanan Pangan, 161.

Arsad, E. 2015. Teknologi Pengolahan Dan Manfaat Bambu. Jurnal Riset Industri Hasil Hutan, 7(1), 45.

Ariyanto, R., Puspitasari, D., dan Ericawati, F. 2017. Penerapan Metode Double Exponential Smoothing Pada. Informatika Polinema, 4, 57 62.

Chang, P. C., Wang, Y. W., and Liu, C. H. 2007. The development of a weighted evolving fuzzy neural network for PCB sales forecasting. Expert Systems with Applications, 32(1), 86-96.

Darmayanti, N. 2016. Model Perencanaan Produksi Untuk Memenuhi Permintaan Pasar Dan Pengendalian Persediaan Produk Jadi Pada Perusahaan Penghasil Minuman Ringan. Jurnal BETA (Biosistem Dan Teknik Pertanian), 4(2), 36-46.

Dharmesta, A. M., dan Susanto, N. (2016). Peramalan Perencanaan Produksi Semen dengan Metode Exponential Smoothing pada PT. Semen Indonesia. None, 5(4), 1-10.

Elvierayani, R. R. 2017. Peramalan Nilai Tukar ( Kurs ) Rupiah Terhadap Dolar Tahun 2017 dengan Menggunakan Metode Arima BoxJenkins. Prosiding SI MaNIs (Seminar Nasional Integrasi Matematika Dan Nilai Islami), 1(1), 253-261.

Faustina, R. S., Agoestanto, A., dan Hendikawati, P. 2017. Model Hybrid ARIMA-GARCH untuk Estimasi Volatilitas Harga Emas. UNNES Jurnal of Mathematics, 6(1), 11-24.

Fitria, V., dan Anwar, S. 2020. Penerapan Triple Exponential Smoothing Dalam Meramalkan Laju Inflasi Bulanan Provinsi Aceh Fakultas
Matematika dan Ilmu Pengetahuan Alam Universitas Syiah Kuala, Aceh. 1, 23-38.

Hingmadi, D. 2012. Kenaekaragaman Ciri Morfologi Jenis Bambu (Bambusa Sp) di Kelurahan Teunbaun Kecamatan Amarasi Barat Kabupaten Kupang. Skripsi. Program Studi Biologi FMIPA Universitas PGRI NTT.

Indah, D. R., dan Rahmadani, E. 2018. Sistem Forecasting Perencanaan Produksi dengan Metode Single Eksponensial Smoothing pada Keripik Singkong Srikandi Di Kota Langsa. Jurnal Penelitian Ekonomi Akutansi (JENSI), $2(1), 10-18$.

Iqbal, M. 2016. Sistem Peramalan Menggunakan Metode Triple Exponential Smoothing Untuk Stok Bahan Spare Part Motor Di Garuda Motor Jajag. 1110651220.

Jong, Y., Wardenaar, E., dan Tavita, G. E. 2018. Studi Jenis Dan Pemanfaatan Bambu Oleh Masyarakat Dusun Perigi Desa Semade Kecamatan Banyuke Hulu Kabupaten Landak. 6(1), 131-136.

Kencana, P. K. D., Widia, W., dan Antara, N. S. (2012). Praktek Baik Budi Daya Bambu Rebung Tabah (Gigantochloa nigrociliata BUSEKURZ). 1-69.

Makridakis, S., Wheelwright, C. S., and McGEE, E. V. 1995. Metode dan Aplikasi Peramalan (Kedua). Erlangga.

Mardhotillah, M., Sutikno, S., dan Fauzi, M. (2014). Pemodelan hujan-aliran daerah aliran sungai rokan dengan menggunakan data penginderaan jauh. 1-12.

Marlina, N., dan Juliani, A. (2015). Evaluasi Daya Tampung Terhadap Beban Pencemar Menggunakan Model Kualitas Air ( Studi Kasus : Sungai Winongo ). 4(2), 78-86.

Nangi, J., Indrianti, S. H., dan Pramono, B. 2018. Peramalan Persediaan Obat Menggunakan Metode Triple Exponential Smoothing (Tes) (Studi Kasus: Instalasi Farmasi Rsud Kab. Muna). Semantik, 4(1), 135-142.

Padma Yanti, N., Tuningrat, I., dan Suryawan Wiranatha, A. 2016. Analisis Peramalan Penjualan Produk Kecap Pada Perusahaan Kecap Manalagi Denpasar Bali. Jurnal Rekayasa Dan Manajemen Agroindustri, 4(1), 72-81.

Puji Lestari, A. 2008. Pengaruh suhu terhadap karakteristik pengeringan rebung bambu tabah. $1-8$.

Rachmawati, L. F. (2016). Rekayasa model sistem dinamik komoditas jagung untuk mendukung program upaya khusus di jawa barat listyani fitria rachmawati. Institut Pertanian Bogor.

Rizal, J., dan Akbar, S. 2015. Perbandingan Uji Stasioner Data Timeseries Antara Metode: 
Control Chart, Correlogram, Akar Unit Dickey Fuller, dan Derajat Integrasi. Jurnal Gradien, 11(1), 1040-1046.

Tanuwijaya, H. 2010. Penerapan Metode Winter ' $S$ Exponential Smoothing Dan Single Moving Average Dalam Sistem Informasi. Seminar Nasional Manajemen Teknologi XI, 1-10.

Tistiawan, T. A., dan Andini, T. D. 2019. Pemanfaatan Metode Triple Exponential Smoothing Dalam Peramalan Penjualan Pada Pt.Dinamika Daya Segara Malang. Jurnal Ilmiah Teknologi Informasi Asia, 13(1), 69.

Tohir, A. 2011. Analisis Peramalan Penjualan Minyan Sawit Kasar atau Crude Palm Oil (CPO) Pada PT. Kharisma Pemasaran Bersama (KPB) Nusantara.

Wardah, S., dan Iskandar, I. 2017. Analisis Peramalan Penjualan Produk Keripik Pisang Kemasan Bungkus (Studi Kasus : Home Industry Arwana Food Tembilahan).J@ti Undip : Jurnal Teknik Industri, 11(3), 135.

Yulianti, F. 2012. Modeling dan Forecasting Tingkat Produksi Gas di Indonesia Menggunakan Metode Autoregressive Integrated Moving Average (Arima). FT UI. 